\title{
MÍDIAS LOCATIVAS E REALIDADE AUMENTADA: POTENCIALIDADES PARA O ENSINO GEOGRAFIA NA CIBERCULTURA
}

Locative media and augmented reality : potentialities for teaching geography in cyberculture

\author{
Wander Guilherme Rocha Carvalho* \\ José Augusto Faria de Araújo** \\ * Mestrando do PPG em Geografia - UNICAMP - wander.grc@gmail.com. \\ ** Mestrando do PPG em Geografia - UNICAMP - gutoujo@gmail.com.
}

Recebido em 06/08/2018. Aceito para publicação em 20/08/2018.

Versão online publicada em 03/09/2018 (http://seer.ufrgs.br/paraonde)

\begin{abstract}
Resumo:
O surgimento de novas tecnologias de informação e comunicação ressignificam o modo de vida humano, a cultura e as relações com o espaço. As mídias locativas, que agregam a um local específico um determinado conteúdo informacional através do acesso à localização GPS, fazem emergir novas espacialidades e potencialidades, como com o uso tecnologia da realidade aumentada (RA), que tem sido difundida e aperfeiçoada com os jogos e aplicativos lançados a cada dia, permitindo a visualização de elementos virtuais no mundo real, em tempo real, o que passa a promover novas possibilidades de interação entre esses elementos e os usuários. Este artigo discorrerá sobre os usos da realidade aumentada e suas potencialidades para a Geografia e o ensino.
\end{abstract}

Palavras-chave: mídias locativas; realidade aumentada; cibercultura.

\begin{abstract}
:
The emergence of new information and communication technologies reconfigures the human way of life, culture and relations with space. Locative media, which aggregate a specific informational content through access to GPS location, brings to the forefront new spatiality and potentialities, such as the use of augmented reality (RA) technology, which has been diffused and improved with games and applications launched each day, allowing the visualization of virtual elements in the real world, in real time, which is to promote new possibilities of interaction between these elements and users. This article will discuss the uses of augmented reality and its potential for Geography Teaching
\end{abstract}

Key-words: Locative media, Augmented Reality; Cyberculture.

\section{Introdução}

No atual período histórico, em que as sociedades e suas relações se constituem e se estabelecem sobre o advento de novas tecnologias, o universo escolar e seus processos e práticas não estão excluídos deste paradigma. De forma alguma estes aparatos tecnológicos representam soluções mágicas para o fim dos problemas escolares no Brasil, mas são elementos tão intrínsecos à realidade humana, com uma ampla diversidade e uma aplicabilidade infinda no processo de ensinoaprendizagem e no desenvolvimento dos saberes geográficos cotidianos, que podem e devem se tornar importantes aliados no Ensino, sobretudo no de Geografia.

Nesta condição que se emerge exponencialmente, no final do século XX e, sobretudo no século XXI, o pensador Pierre Lévy ao publicar seu trabalho Cibercultura (1999), reflete sobre os impactos das novas tecnologias na construção do saber das sociedades contemporâneas. Neste advento, que o autor denomina de Cibercultura, em que a sociedade é condicionada pelo surgimento de um Ciberespaço. 
O termo [ciberespaço] especifica não apenas a infraestrutura material da comunicação digital, mas também o universo oceânico de informação que ela abriga, assim como os seres humanos que navegam e alimentam esse universo. Quanto ao neologismo 'cibercultura', especifica aqui o conjunto de técnicas (materiais e intelectuais), de práticas, de atitudes, de modos de pensamento e de valores que se desenvolvem juntamente com o crescimento do ciberespaço (LÉVY, 1999, p. 17).

Segundo Lévy (1999), cada vez mais as pessoas aprendem fora dos sistemas acadêmicos e escolares, por este viés, o sistema educacional deve se preparar para a nova configuração da era da Cibercultura, uma vez que as constantes inovações das tecnologias educacionais requerem novas metodologias de ensino que ressignificam o processo de cognição, à medida que "os indivíduos aprendem cada vez mais fora do sistema acadêmico" (ibid., p.175).

Ao trabalhar com o conceito de virtual, Levy discorre que não necessariamente virtual se opõe ao real, muitas vezes o virtual é uma representação da realidade, e nem mesmo se opõe ao material, embora que ocupe um espaço físico muito menor que a realidade que ele apresenta. Assim ao se trabalhar com jogos virtuais (ou com as mídias permitidas pelas novas tecnologias), em muitos casos, não deixamos de lado a realidade.

Lucia Santaella (1992) nos traz em diferentes publicações, muitos conceitos e visões de significativa importância acerca da temática. Entre suas contribuições, a autora aborda o conceito de cultura das mídias, que para ela deve ser compreendida como uma interação entre muitos processos e códigos que atuam nas mídias em seu sentido cultural, assim existe uma singularidade nos efeitos de percepção e comunicação que são produzidos nos receptores, o que é diferentemente do ocorrido à cultura de massa esta que é uma "pasta homogênea e disforme de mensagens" (SANTAELLA, 1992, p.30).

Para Santaella (1992), fenômenos comunicativos também são fenômenos culturais, e são processos que estão intimamente conectados. Ao definir o significado de cultura, a autora o condiciona diretamente com a Semiótica, ou seja, a ciência dos signos. Para ela, o foco da semiótica está nos meios comunicacionais, ou seja, para a produção de sentidos como são processados e utilizados pelo homem através de seus meios e modos. "Todo esforço da semiótica se endereça para a investigação dos modos como os mais diferenciados processos de linguagem engendram-se, codificam-se e funcionam comunicativamente e culturalmente" (p.27).

A cultura é parte do ambiente feito pelo homem, ou seja, está relacionada com ações, ideias e artefatos que os indivíduos aprendem, compartilham e avaliam. E vai além, pois soma todos os elementos do legado humano, adquirido através dos grupos sociais pela aprendizagem consciente. Entende-se, portanto, que tudo aquilo que é visto como uma organização ou regulação da vida social, dos comportamentos e costumes, pertence à cultura. (SANTAELLA,1996). A autora afirma

Costumes, crenças, ferramentas, técnicas difundem-se de uma região para outra, de um povo para outro. Os elementos culturais têm assim uma história cronológica. Isso envolve questões tais como origem, crescimento e diferenciação cultural através da história (SANTAELLA, 1997, p.43).

Com a atual gama tecnológica, e que ainda é desenvolvida ao passar dos anos, temos uma sociedade transformada em todos os aspectos, especificamente no meio comunicativo e informativo. Qualquer que seja a mediação atrelada à difusão informativa, ela será inerente à socialização e à cultura, e, portanto, ao homem. 0 advento de cada inovação traz consigo um ciclo que lhe é próprio, devido à noção que lhe é dada, caracterizada pelos modos de relação. (SANTAELLA, 2011)

0 ritmo das mudanças culturais varia, sobretudo, atualmente, de forma extraordinária. Isso por causa da possibilidade em que a sociedade globalizada apresenta para que tal desenvolvimento se realize. Pensando nisso, o desenvolvimento dos meios de divulgação da informação, a partir da 
emergência das tecnologias digitais, mudou nossos padrões de comportamento. A mudança cultural dos modos de socialização causadas pela revolução digital também tem contribuído para projetar a civilização em direção à era da informação, caracterizada pela adoção em massa dessas tecnologias em todas as esferas de nossas vidas (CASTELLS, 1996). De acordo com Santaella:

A sequência de mudanças nos dispositivos de análise da comunicação e cultura no século XX funciona como um indicador das impressionantes transformações, por que os fenômenos culturais vêm passando, transformações essas primeiramente devidas à exploração dos meios de comunicação de massa que prevaleceu até os anos 80 , e atualmente devidas à onipresença da realidade midiática (1997, p. 66).

O surgimento de novas tecnologias de informação e comunicação resignificam o modo de vida humano, a cultura e as relações com o espaço. Tais tecnologias em suas diferentes formas, tem desde as primeiras cidades transformado os espaços urbanos. Nas cidades na cibercultura, em que nos últimos anos houve uma gigantesca popularização dos dispositivos smartphones e iphones, e do acesso à estes aparelhos a internet móveis, emergem-se as mídias locativas, que agregam a um local específico um determinado conteúdo informacional através do acesso a localização GPS, surgindo assim novas espacialidades.

Uma das tecnologias que vem sendo usada nos dispositivos móveis é a de Realidade Aumentada (RA), que proporciona ao ser utilizada em uma mídia locativa, a possibilidade de inserir informações e conteúdos virtuais em um determinado local em tempo real, o que passa a promover novas possibilidades e potencialidades de interação entre estes elementos virtuais, os lugares e os usuários. Portanto, a realidade aumentada aparece uma ferramenta de apropriação das cidades e ressignificação dos espaços e também pode se tornar uma ferramenta poderosa no processo de ensino e aprendizagem.

Não podemos negar que está emergindo nas últimas décadas um novo tipo de sujeito/estudante com novas capacidades e novas necessidades. Assim, este artigo buscará explorar quais as potencialidades da Realidade Aumentada para a Geografia, e investigar como esta tecnologia pode ser incorporada no ensino, levando em consideração as dimensões da ubiquidade e da interatividade.

\section{Mídias Locativas}

Considerando como fator chave as relações entre o espaço e as novas tecnologias e surgindo do resultado direto das tecnologias móveis, as mídias locativas possibilitam novas possibilidades de interações entre os lugares e banco de dados em diferentes contextos, caracterizando-se como tecnologias que utilizam dos Sistemas de Posicionamento Global (GPS). 0 que pode ser elucidado na passagem de Santaella (2008, p.32), ao referir as mídias locativas como " um campo em que a localização de pessoas e objetos pode ser usada pelas máquinas para derivar informação contextual com a qual dão assistência aos usuários".

André Lemos (2008) define mídia locativa (locative media) como um conjunto de tecnologias e processos info-comunicacionais cujo conteúdo informacional vincula-se a um lugar específico. "Sendo dispositivos informacionais digitais cujo conteúdo da informação está diretamente ligado a uma localidade. Isso implica uma relação entre lugares e dispositivos móveis digitais até então inédita." (Lemos, 2008).

Atrelado às mídias locativas temos novas práticas de mobilidade comunicacional que surgem a partir de novas relações sociais com o espaço (LEMOS 2008). Observamos cada vez mais presente a cultura baseada nestes dispositivos de geolocalização, aplicativos como o Waze e o Google maps, são utilizados por milhares de pessoas nas cidades brasileiras todos os dias. Santaella (2008) vai chamar 
este fenômeno de Cultura da Mobilidade, o que para ela nada mais seria do que "uma variação avançada da cibercultura" (Santaella, 2008) Percebe-se que ao ativar a localização dos dispositivos móveis surge uma imensa camada informacional digital, mas que em sua maioria está associada ao consumo. Nas proximidades aparecem lojas, restaurantes, estabelecimentos relacionados com suas últimas pesquisas nos navegadores. No caso do aplicativo Waze, por outro lado, observa-se massivamente o caráter colaborativo das mídias locativas, que proporcionam aos usuários o compartilhamento de informações relacionados à determinadas localidades, como por exemplo adversidades na rodovia, condições de trânsito impedido em alguma rua, ou até mesmo barreiras policiais e radares.

\section{Realidade Amentada (RA):da resignificação do espaço urbano ao Ensino de Geografia}

A presente cultura de mídias tem uma interface com o ensino focalizando-o em ambientes virtuais. É possível fazer uma relação com metodologias de ensino e de aprendizagem uma vez que se pensa nos indivíduos que atuam de forma ativa nesse sistema informativo como uma nova sensibilidade e receptação relacional aos novos meios de informação. As interações, o modo de posicionamento e a transposição social através das redes estão extremamente mediadas pelos dispositivos digitais. As atividades que antes haviam a necessidade de relação com diversos equipamentos, podem, hoje, ser feitas apenas com o uso de um aparelho smartphone. A mente dos indivíduos está se estendendo para que seja possível incorporar o mundo ao redor. Há a preocupação em fazer as conexões dos meios de acesso à informação, ao invés de se decorar o caminho ou lembrar o nome das pessoas, por exemplo. Cria-se, portanto, uma nova noção de relação social-espacial.

A popularização, por exemplo, do sensoriamento remoto e seus usos nos campos educacionais e científicos vêm aumentando exponencialmente nas últimas décadas. Este processo proporcionado pelos programas de localização em conexão via internet, como o Google Maps e o Google Earth, que utilizam de imagens geradas através de satélites por sensores orbitais, com uma qualidade cada vez melhor e a fácil disponibilidade. Sendo assim, a tecnologia da realidade aumentada (RA) tem sido difundida e aperfeiçoada com os jogos e aplicativos lançados a cada dia, permitindo a visualização de elementos virtuais no mundo real, em tempo real, o que passa a promover novas possibilidades de interação entre esses elementos e os usuários.

É necessário distinguirmos brevemente os conceitos de realidade virtual e realidade aumentada (RA), que embora ambos estejam muito relacionados há forte uma tendência em uma confusão entre esses dois conceitos distintos. Pode-se admitir que enquanto na realidade aumentada (RA) o ambiente real é enriquecido com elementos virtuais, na virtual todo o ambiente é gerado através do computador. (KIRNER; TORI, 2004).

A realidade virtual adentra em um mundo tridimensional (3D), enquanto que na RA o 3D que se insere no mundo ao redor do usuário, significando que na prática, as interações entre os elementos virtuais e o homem são trazidas como se esses elementos estivessem no mundo real, sendo possível a manipulação e a interação com esses elementos. (GIROTO; MIRA, 2016).

Na percepção de Santaella é a partir da combinação de objetos virtuais em 3D com o ambiente real, ou a partir da sobreposição de informações digitais no espaço físico havendo a predominância do real chegamos ao conceito de realidade aumentada. (SANTAELLA, 2007).

A realidade aumentada (RA) é utilizada nos jogos Pokemón Go e Ingress, disponíveis gratuitamente para download nos sistemas android e IOS e que vem sido bastante utilizados no Brasil por usuários de diferentes perfis. A febre do início dos anos 2000 no Brasil, volta em uma condição de RA criado pela norte-americana Niantic, no jogo Pokemón Go para encontrar os pokemóns e capturá-los é necessário a interação com o mundo real. Um desses pokemóns pode ser encontrado na vizinhança do jogador, por exemplo, e pode ser capturado por meio de uma luta virtual através do smartphone do 
jogador com o auxílio da câmera e localização GPS.O objetivo do jogo é capturar o maior número de pokemons possiveis, o cenário do jogo é a própria cidade que o jogador está ou o próprio bairro, ou seja, as ruas, praças e espaços públicos abertos. Sobrepostos a realidade trazida a tela dos smartfones

Já o Ingress, é um jogo de RA que originou o Pokemón Go, ambos são dos mesmos criadores, a diferença é que a proposta do Ingress não é de capturar pokemóns, mas sim baseado em uma ficção científica em que "energias", obviamente que virtuais, se emanam do chão em alguns pontos das cidades e o objetivo e o desvendamento dessas forças.Mesmo que ambos os jogos trabalham com elementos virtuais fictícios, eles colocam seus usuários em contato com as cidades e seus espaços, e necessitam de um conhecimento geográfico como, por exemplo, para se locomover pelos mapas apresentados.

Essas tecnologias de RV e de RA estão mudando também as formas de relação das pessoas com o ambiente em que vivem (PEREIRA; FLORENTINO; ROCHA, 2013). A ubiquidade das tecnologias da informação está produzindo ambientes que são completamente diferentes de tudo o que se experimentou até agora. De acordo com Billinghurst and Dunser (2012) - apud Silva, Vilar, Reis, Lima e Teichrieb (2014) - A RA também facilita a compreensão de fenômenos complexos fornecendo experiências visuais e interativas únicas através da combinação do real com o virtual, além de auxiliar na comunicação de problemas abstratos aos aprendizes. Portanto, fica evidente o potencial da RA para o Ensino de Geografia.

Diferentes projetos e estudos com RA vem evidenciando a riqueza de possibilidades de se trabalhar com essas ferramentas geograficamente. Um dos projetos recentes é o Projeto Memórias Soteropolitanas, trabalho de conclusão de curso da Camila Queiroz, apresentado ao curso de Jornalismo da Universidade Federal da Bahia, sob orientação do Prof. Dr. André Lemos com trabalhos já citados neste artigo. 0 projeto proporciona através de uma combinação de um site com informações georreferenciadas e pelo uso do aplicativo layer, que no caso, utilizando fotografias e postais antigos de Salvador, proporciona a experiência de utilizar a RA para visualizá-las exatamente no mesmo local e orientação que os locais na atualidade. O Memórias Soteropolitanas apenas como um exemplo de práticas que devem ganhar força à medida que proporcionam experiências de resgate da memória local, de apropriação do espaço urbano e de inclusão digital, criando deslocamentos temporais e reflexão sobre o espaço.

São assim, excelentes experiências para que o cidadão das modernas metrópoles possa ter uma experiência diferente dos lugares por onde passa comumente sem prestar muita atenção. São projetos interessantes, pois propõem usos diferenciados dos telefones celulares, das redes e do espaço urbano. (LEMOS; QUEIROZ, 2012).

No Ensino de Geografia expandem-se as alternativas no processo de ensinoaprendizagem. Por um lado, a realidade aumentada pode ser utilizada na visualização de conteúdos virtuais, como por exemplo uma maquete virtual, também como um recurso complementar ao livro e apostilas, como alguns que já trazem em alguns conteúdos um QR code que ao utilizar a câmera cria um determinado conteúdo virtual. Outras e mais ricas possibilidades é quando pensamos a Realidade Aumentada em dispositivos móveis, como uma mídia locativa, podendo agregar qualquer conteúdo informacional a um posicionamento georreferenciado, seja fotos, textos, vídeos, músicas, etc. Neste ponto encontramse os espaços físicos e virtuais, e a riqueza de informação que pode ser adicionada ao lugar o ressignificando.

\section{Uma aprendizagem ubíqua e interativa}

Vive-se hoje em um contexto onde os aparelhos tecnológicos móveis estão presentes na vida das pessoas como ferramentas adicionadas ao corpo para realização de tarefas cotidianas, como o 
deslocamento, a busca de informações e a comunicação. A mídia locativa se apresenta, nesse caso, como uma extensão da cognição do humano e permite uma interpretação e relação com os signos do espaço urbano a partir de uma nova forma de viver, pensar e saber.

"A mídia, há muito tempo assumiu a função do ensino", é o que afirma Michel Serres (2013, p. 19). Os jovens de hoje em dia, ou seja, aqueles que possuem uma mentalidade estritamente relacionada às novas mídias, não se desligam do mundo virtual e tem como companheiros os aparelhos que são suporte para ferramentas tecnológicas. Com a difusão dos das redes de internet, a comunicação, que costumava ser predominantemente unidirecional, passou a ser caracterizada pela capacidade de envio de mensagens a partir de muitos para muitos de maneira assíncrona (DI FELICE, 2007). Esses novos sistemas de comunicação reformularam e potencializaram os processos de obtenção, sistematização, representação e construção da informação e do conhecimento (LÉVY, 1993). Lévy (2009) mostra, em seus estudos, como as novas tecnologias do ciberespaço podem ajudar a criar uma circulação do saber através "Inteligência Coletiva". Essas novas práticas se atrelam ao termo "ciber-cultura-mix". De acordo com Lemos (2005), essa nova forma do fazer é a expressão de uma lógica recombinante que abusa de processos abertos, coletivos, inacabados. Ou seja, cria-se uma ISSN: 2175-8875 www.enanpege.ggf.br/2017 3768 configuração de circulação e a criação de bens de serviços com as novas tecnologias a partir de práticas de combinação. Essa forma de produção de conteúdo caracteriza um sujeito em específico, que é o leitor ubíquo. Seu perfil é determinado pela atenção parcial e continua, sua atenção é dada ao mesmo tempo a múltiplos focos e sem reflexões perenes em qualquer um deles.

Os alunos que cresceram no interior de uma mentalidade ciberespacial, muitas vezes veem e abordam o mundo de forma diferente. A multitarefa se tornou onipresente na era digital. Além disso, este modo de realizar as coisas não é limitado ao lazer e comunicação, mas se apresenta como um modo de aprender (LANKSHEAR; KNOBEL, 2007)

A aprendizagem ubíqua não deve substituir a educação formal, porém, elas devem se complementar. Um dos maiores desafios da educação atual talvez seja essa complementariedade. Observamos alguns indícios que a aprendizagem ubíqua e interativa vem acontecendo, inclusive, as vezes até mesmo dentro dos ambientes escolares, onde os alunos estão de fato dialogando com o ambiente exterior. Certamente ela deve ganhar força nos próximos anos, mas ainda não há como mensurar o quão positivo ou negativo este paradigma atuará na educação. Porém, devemos aproveitar estas possibilidades para enriquecer o conhecimento e a Geografia, uma vez que elas surgem fortes como mecanismos de novos letramentos e relações com os sujeitos, as cidades, os espaços e os lugares.

\section{Referências}

GIROTO, L. M.; MIRA, J. E. Tecnologias emergentes no ensino a distância: realidade virtual, realidade aumentada e uma proposta de utilização do cardboard. Bauru, 2006.

KIRNER, C.; TORI, R. Introdução à Realidade Virtual, Realidade Misturada e Hiperrealidade. São Paulo: Mania de Livro, 2004.

LANKSHEAR, Colin; KNOBEL, Michele. New Literacies Sampler: Chapter 1: Sampling "the New" in New Literacies. New York, 2007.

Lévy, Pierre . As tecnologias da inteligência, 1993

Cibercultura. São Paulo: Editora 34, 1999.

LEMOS, A. Cibercultura. Tecnologia e Vida Social na Cultura Contemporânea., Sulina, PortoAlegre., 2002

Mídias Locativas e Territórios Informacionais. In L. santaella, P. Arantes (eds.) estéticas Tecnológicas. novos modos de sentir. São Paulo, educ., 2008, pp. 207-230 
LEMOS, A.; QUEIROZ, Camila . Memórias Soteropolitanas: Realidade aumentada na cidade de Salvador. Inclusão Social (Online), v. 5, p. 128-136, 2012.

POSSA, Leandra Bôer. Metodologia da Pesquisa. IN: SILUK, Ana Claúdia Pavão (org.) Curso de Especialização à Distância em Educação Especial. Santa Maria. UFSM, CE, 2008.

RICHARDSON, R.J. Pesquisa Social: métodos e técnicas. 3. ed. São Paulo: Atlas, 2009.

SANTAELLA, Lúcia. A assinatura das coisas: Peirce e a literatura. Rio de Janeiro: Imago, 1992.

Linguagens líquidas na era da mobilidade. São Paulo. Paulus, 2007.

2009. Matrizes da linguagem e pensamento: sonora, visual, verbal. 3. ed. São Paulo: Iluminuras, Cultura das Mídias. São Paulo: Experimento,1996.

Da cultura das mídias à cibercultura: o advento do pós-humano. Revista FAMECOS, Porto Alegre, nํㅡ 22, dezembro 2003.

SERRES, Michel. Polegarzinha: uma nova forma de viver em harmonia e pensar as instituições, de ser e de saber. BERTRAND BRASIL, 2013.

SILVA, Manoela; VILAR, Edvar; REIS, Guilherme; LIMA, João Paulo; TEICHRIEB, Veronica. AR Jigsaw Puzzle: Potencialidades de Uso da Realidade Aumentada no Ensino de Geografia. In: XXV Simpósio Brasileiro de Informática na Educação, Dourados, 2014. 